Article

\title{
Sustainability and Its Place in the Self-Determination of Information-Based Companies
}

\author{
Michał Baran (D) \\ Institute of Economics, Finance and Management, Faculty of Management and Social Communication, \\ Jagiellonian University, ul. Łojasiewicza 4, Room 2.378, 30-348 Kraków, Poland; michal.baran@uj.edu.pl
}

Received: 2 April 2020; Accepted: 15 June 2020; Published: 18 June 2020

\begin{abstract}
The term sustainability is understood in many different ways. Its interpretation determines the behaviors of those who want to include the idea into their actions. The question, therefore, arises about how individual entities understand the term sustainability and how they express their vision in this regard. This issue is largely qualitative and requires the use of qualitative data analysis tools. In this context, information-based companies are a special case because they are free of burdens that affect enterprises with roots in the traditional economy. Attitudes towards the idea of sustainability in this group of enterprises are of the most voluntary nature. In the present discussion, the thesis was adopted that the context in which the entity refers to the idea of sustainability reveals the dimensions within the framework of which the entity determines its attitude to this idea. In the present discussion, the subjects of interest were exclusively the semantic categories of the context and not the typology of organizations using such semantic categories. A qualitative analysis (carried out on the basis of linguistic analysis) of the annual reports-a purposive sample of 20 selected enterprises and sector leaders whose activities are based on data processing — submitted to the US Securities and Exchange Commission has allowed us to identify four dimensions of self-determination in the context of sustainability (the detection of these dimensions was the main purpose of the conducted analysis). Due to the method used, which involved examining the linguistic significance of individual words and in accordance with scientific rules, the requirement of representativeness did not apply to the collected data. However, the data had to show the various concepts currently used (even if only once) by sector leaders in their public discourse. The detected dimensions are divided into two groups: internal, where two types specified as BASE and ROLE are listed, and external, with two successive types hidden under the names IDEA and CARE.
\end{abstract}

Keywords: organization mission; company image; stakeholders priorities; digital economy

\section{Introduction}

The idea of sustainability has gained a lot of recognition in management practice over the past few decades. In addition to the emergence of the digital economy, it is one of the most important phenomena shaping the area of scientific considerations devoted to the organization of human activities in the modern world [1]. However, due to the dynamic development of human knowledge in this area, many questions remain pending an answer. The term sustainability is understood in many different ways. There is some competition here among attempts to describe the term, which sometimes creates interpretation difficulties that are important for managers to overcome [2]. This is due to the fact that the way of interpreting sustainability is crucial for the future interests of decision-makers, such as what will focus their attention and what priorities they will adopt. The question, therefore, arises about how individual entities understand the term sustainability and how they express their vision in this regard. The key problem here is to identify general dimensions (semantic categories) [3] within which individual entities refer to the issue of sustainability. The answer to this question can 
be given by analyzing the most important documents, such as enterprises' annual financial reports. These types of documents are signed by corporate management boards and play a fundamental role in the processes of communicating with stakeholders and the state (in the case of the USA, represented by the Securities and Exchange Commission) [4]. A financial report is a very specific document because it contains a synthesis of key problems identified by management and, therefore, declarations made on this occasion are a form of public commitment. The issue of the analysis of reports (for the purpose of present consideration) is largely qualitative and requires the use of qualitative data analysis tools. In this context, information-based companies are a special case because they are free of burdens that affect enterprises with roots in the traditional economy [5]. Information-based enterprises can consciously choose the priority directions of their activities and define their place in relation to the environment, usually without having to take into account pressure from groups submitting any type of claim. Attitudes towards the idea of sustainability in this group of enterprises mostly of the voluntary nature. It can, therefore, be assumed that the observations made in this respect in relation to information-based companies allow us to track the declarations regarding most important problems, which reflect not external pressure but the real level of awareness of the top management staff responsible for the generalized self-determination of the company and the selection of its strategic activities. The specificity of qualitative research involves searching for the context structure, regardless of quantitative parameters [6]. As in the case for focus groups or brainstorming, it does not matter who uses a term or how many times a wording is used. In the case of the enterprises included in the research, it is only important that some wording appeared in the public forum (even if it happened in only one case). Each individual observation has the same importance, regardless of whether it was repeated in the population under consideration and regardless of who the object of observation was. Therefore, in this type of qualitative research, the requirement of representativeness is pointless. The significance of each observation is determined only by the fact that the data source is a collection of the most synthetic documents containing the essence of what is most important from the perspective of key industry representatives. The analysis is about determining the boundaries of the publicly used context and the criteria of its division. In the present discussion, the thesis was adopted that the context in which the entity refers to the idea of sustainability reveals the dimensions (semantic categories) within the framework of which the entity determines its attitude to this idea. The purpose of the article is to show such potential dimensions of self-determination (in the context of sustainability) based on a qualitative analysis of financial annual reports provided to the US Securities and Exchange Commission. To determine the dimensions, a purposive sample was used (the data were selected on purpose to show the examples of their diversity), consisting of 20 selected enterprises-leaders of sectors which base their operations on information processing. Such enterprises are the object of observation conducted by numerous stakeholders and they significantly influence the framework of public discourse. Defining these types of dimensions (semantic categories) has a very important practical significance, limiting the controversy that may arise while trying to classify the universal attitudes of the organization towards sustainability. This is because these dimensions are an additional classification tool and should be treated as a compatible and complementary tool ("common denominator") to those classifications that were described in the literature. A comprehensive comparison of the classifications (known from the literature), based on the proposed dimensions, are presented in the final part of the article.

\section{Background}

\subsection{Environment of Observation of Dimensions of Self-Determination Which Are Defined from Sustainability Perspective}

The approach to the idea of "sustainability", adopted in the present discussion, assumes making a reflection on the ways of describing the analyzed phenomenon from the perspective of the role it plays in shaping the organization's value system. Using this type of deductive approach, the axiom of differentiation of particular ways of describing the concept of "sustainability" comes to the fore because of different sets of values, goods or entities that should be taken care of. Objects that are included 
in the spectrum of interest of a particular definition can focus, to a different degree, on phenomena occurring inside the organization, appearing in the environment as a result of the organization's operation or being independent of it. The manner in which the challenges related to these objects are presented also defines the scope of ethical activities that the organization should take [7]. The question, therefore, arises as to the kind of context within which the organizations in practice refer to the idea of sustainability.

The analysis of the content of corporate reports, which was prepared in 2017 by N. Landrum and B. Ohsowski (conducted to understand worldviews of corporate sustainability, or the corporate message conveyed regarding what sustainability is), reveals that there are multiple coexisting worldviews of corporate sustainability, but the most dominant worldview is focused on the business-based justification referring to sustainability, and on the position anchored in the weak sustainability paradigm [8]. A. Calabrese, R. Costa, N. Levialdi-Ghiron and T. Menichini proposed in 2019 a tool of evaluation of narrative adequacy (in the form of a matrix) which supports the evaluation of the transparency and effectiveness of corporate sustainability communication [9]. Such a tool—based on the idea of a structured approach to discovering meanings-is focused on overcoming the uncertainty, subjectivism and vagueness affecting judgements, which by its nature is qualitative (interpretative). This idea supplements the well-known Global Reporting Initiative (GRI) materiality matrix, which in 2013 for the sector of Software and IT Services Enterprises identified 33 topics of narration (ordered according to the scheme: Category, Topic, Specification, Constituency) [10]. It should be noted, however, that these matrices represent an approach based on the arbitrary determination of narrative categories. Meanwhile, in the practice of economic life, narrative is the effect of many real factors. So, it may turn out that the "bottom-up" approach (i.e., observation of a disordered set of narratives) (and the search for the natural dividing axes written inside the set) would allow us to divide this set according to categories that more accurately present the way of looking at this issue by managers actively participating in the market game. This viewpoint is developed in the empirical part of the presented considerations.

Research results published in 2020 by T. de Mendonc and Y. Zhou have proved that the motivation for actually incorporating the idea of sustainability by a wider group of companies is primarily the orientation that characterizes industry leaders (neither the expectation of government regulation nor social movement pressure was found to be influential on such motivation) [11]. The results of the research by R. Hanohov and L. Balacchino from 2018 indicate that there is a relationship between a manager's inclination to support initiatives consistent with the idea of sustainability and the scope of entrepreneurial experience that he has-especially if this experience was acquired in an international environment (which is often the case with the highest level of management staff in major global corporations) [12]. Such a set of practical pieces of experience is, therefore, a kind of trigger. However, in the first place, the manager shapes his knowledge about sustainability under the influence of theoretical descriptions of this phenomenon. Thus, understanding what image is presented to him on this occasion allows us to later assess the correctness and the way he refers to this idea.

By combining descriptions of the abovementioned circumstances, it is possible to propose a comprehensive and coherent model of the environment, in which the observations of the dimensions of self-determination from a sustainability perspective would be made, as shown in Figure 1. In this model, the theoretical approach to the idea of sustainability is introduced by the elite of the top management staff into the organizational value system within the framework of the process of catalysis, which is shaped by their wide and international practical experience. Thanks to this, a narrative of industry leaders is created, which dominates in public discourse and thus shapes the way all other enterprises look at reality. Such a narrative can be studied primarily with the help of methods of qualitative data analysis, because its character is reflected not in the statistics of the words used, but in the relationships between them and the configurations of the observed associations. These are methods of analysis very well known in the field of management science in the area of organizational psychology and sociology and are used to prepare subsequent and well-founded quantitative research. It should be very strongly emphasized that the size of the studied sample does not matter at the stage 
of qualitative research because the analysis effect is not used for statistical generalization but is only used as evidence of the actual existence of a phenomenon with an unknown frequency of occurrence in the entire population. This is an objective limitation of the results of qualitative research; however, this can be eliminated during subsequent quantitative research. Conducting qualitative and then quantitative research leads to the enrichment of knowledge about sustainability and the creation of theories that shape managers' awareness. In this way, as part of the feedback (while, in parallel, also taking into account the evolution of the practical experience of managers, which occurs under the influence of such a conceptually-oriented real competitive struggle that takes place inside the industry), the model closes.

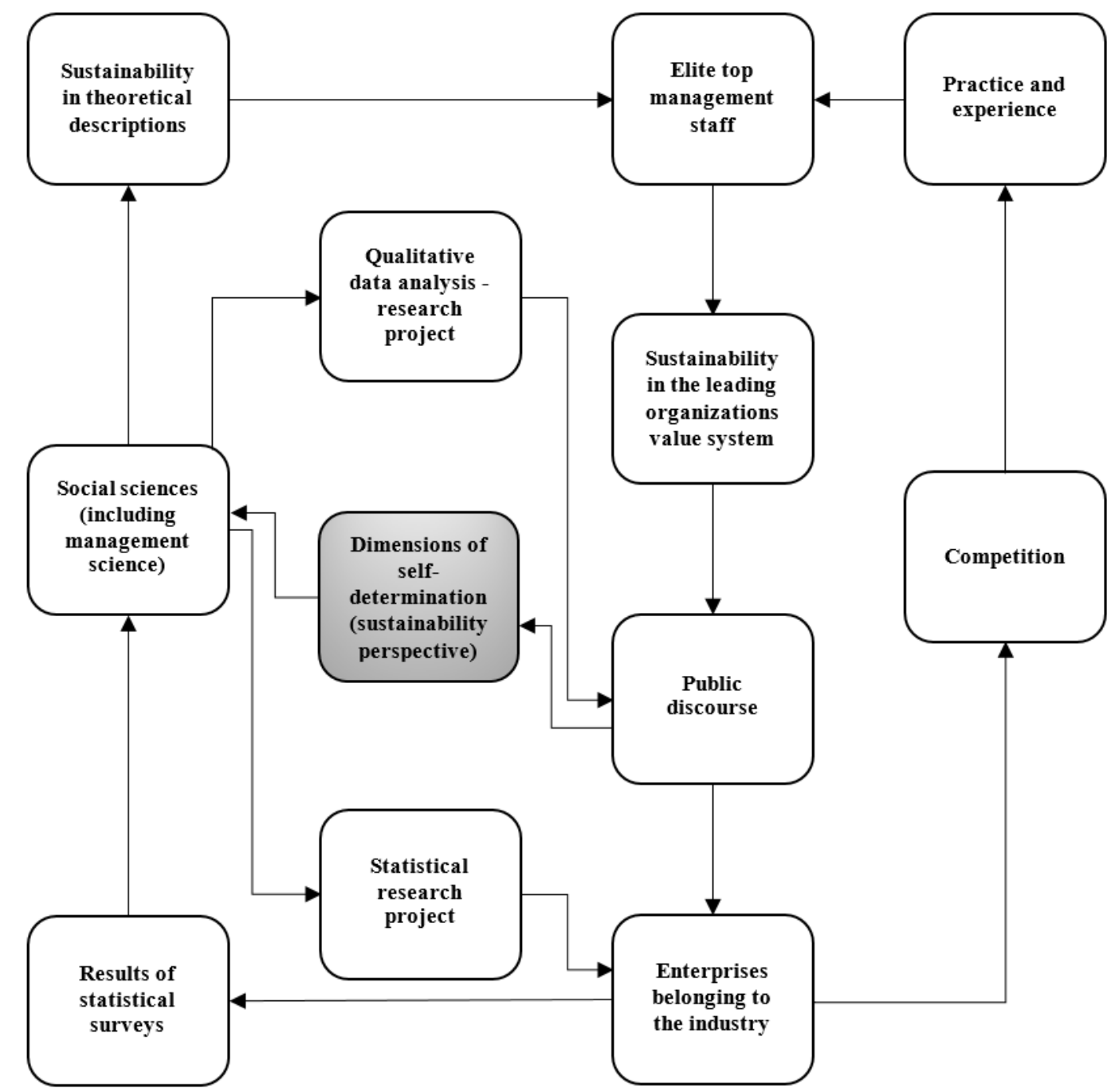

Figure 1. Model of environment of identification of dimensions of self-determination from the perspective of sustainability. Source: Own research.

In the light of comments made about the special role of industry leaders in shaping the narrative devoted to the idea of sustainability, an important assumption was made in the considerations. Due to the role of the leaders, only the largest global IT companies that consciously refer (as part of their annual financial statements) to the idea of sustainability were of interest. This means that the empirical part of the study is based on the analysis of data collected while using a purposive sample. The criterion of striving for achieving the theoretical saturation of analytical data determines the size and composition of the deliberately selected sample. This postulate means striving for the research material that would represent sufficient diversity in order to discover the original structuring of the sample [13]. 
In light of the topic of the present considerations, such a postulate may mean collecting data from corporation documents that are diverse, due to some aspects of their relations with the environment. In the case of the analyzed types of corporations, they may be listed on the NASDQ or NYSE stock exchange, may have their seats in the USA or abroad, may differ due to capitalization or may differ due to the degree of common recognition. Taking into account such a diverse set of enterprises (although those included are only those that belong to one sector and clearly show sensitivity to the issues raised in the analysis) allows us to observe different ranges of narrative devoted to one common idea, which is sustainability (of course, the study refers to the exploration of the narrative used by sector leaders within the Western model of market economy). In the empirical part of the study, it should be expected that, with each subsequent document that was attached to the examined set, the number of words that are a repetition of previously noted ones will increase. If so, this phenomenon will confirm the expected data saturation. According to the experience of other researchers who conducted similar qualitative exploratory analyses, a set of 20 source documents will be sufficient to obtain such result [14].

Thus, it cannot be said that keeping a narrative devoted to the idea of sustainability is a behavioral representative of the entire population of entities constituting the studied industry. Bearing in mind the adopted assumption (regarding the selection of the sample), the very fact of the potential existence of dimensions of self-determination (that would be detected) might be objectively confirmed. However, it is possible that, if the entire population of similar enterprises were taken into account, further dimensions of major importance would appear. This is a significant limitation of the presented considerations in their empirical part, but it is justified due to the desire to learn about the dimensions of the self-determination characteristics of the opinion-forming industry leaders. The leaders play a key role in shaping the narrative in force within the industry (considered as a whole). The graphic model presented in Figure 1, therefore, allows for a better understanding of what shapes the key dimensions of self-determination, that are the subject of consideration, and what the potential area of use of these dimensions is.

\subsection{An Outline of Theories Shaping the Way Managers Perceive the Idea of Sustainability}

The necessity of taking into account the principles of sustainability by every enterprise (regardless of the industry in which it operates, even when it comes to activities in the sphere of digital economy) has become evident as a result of analysis carried out by experts in the field of examining the causes and effects of the financial crisis that took place in the first decade of the current millennium [15]. It can even be said that, currently, the sustainability paradigm [16] is in force and this idea today covers practically every aspect of a company's operations [17]. Contemporary extended concepts of defining value for customers lay the emphasis on resource integration and value in use, which can be offered within the right scope and form when the consideration of the idea of sustainability takes place on the strategic level [18]. In addition, the fact is that the current situation in the capital markets proves that value migrates to the Sustainable Business Models of Digital Economy Companies [19]. This happens in the context of the challenges bound with the creatiom of Sustainable Business Models, which form a set of the following six items [20]:

1) Triple Bottom Line-this challenge is related to the postulate of maintaining a balance between profits and social and environmental benefits.

2) Mind-set-this challenge is related to the postulate of eliminating mental restrictions imposed by rules, guidelines, behavioral norms and performance metrics.

3) Resources - this challenge is related to the postulate of eliminating inertia and internal resistance to organizational changes on the way to creating innovative solutions.

4) Technology innovation - this challenge is related to the postulate of multidimensional integration of complex technological innovations in order to achieve a synergy effect.

5) External relationships-this challenge expresses the need for creative engagement in interactions with stakeholders and the business environment. 
6) Business modelling methods and tools-this challenge expresses the need for the creative use and development of existing business modelling methods and tools.

The first of the above challenges refers to one of the most popular concepts of sustainability, emphasizing the importance of maintaining the right balance between social and environmental performance in addition to financial performance [21]. The basic weaknesses of the Triple Bottom Line (TBL) are associated, among others, with its reductive nature, inertia in agreeing the optimal policy between the organization and its environment, the lack of an external control and coordination center, identification of ecology with the environment, no clear relationship with time assessment, no comparability of what is to be assessed jointly and limited usefulness in management practice [22-24]. The TBL concept tends to focus on short-term actions in contrast to one of the competing, holistic proposals, which is long-term-oriented and is called The Natural Step [25] (this feature of the TBL-short term perspective-can also be assessed as its weakness). The Natural Step proposes four basic but excessively general rules that should be applied by enterprises (that want to be considered among those that in practice apply the idea of sustainability):

1) In a sustainable society, nature is not subject to systematically increasing concentrations of substances from the earth's crust (such as fossil $\mathrm{CO}_{2}$, heavy metals and minerals).

2) In a sustainable society, nature is not subject to systematically increasing concentrations of substances produced by society (such as antibiotics and endocrine disruptors).

3) In a sustainable society, nature is not subject to systematically increasing degradation by physical means (such as deforestation and the draining of groundwater tables).

4) In a sustainable society there are no structural obstacles to people's health, influence, competence, impartiality and meaning.

Among the attempts to create a comprehensive typology of Corporate Sustainability, there stands out the proposal presented by M. M. Bergman, Z. Bergman and L. Berger. This typology includes three types and nine subtypes and was based on analyses of the academic literature on the conceptualization of corporate sustainability [26]. According to the authors mentioned above, sustainability is defined as follows:

1) Corporate sustainability in relation to corporate responsibility (CS and $\mathrm{CR}$ )

1a) Corporate sustainability is similar to corporate responsibility (cs $\approx \mathrm{cr}$ )

1b) Corporate sustainability is different from corporate responsibility ( $\mathrm{cs} \neq \mathrm{cr}$ )

1c) Corporate responsibility leads to corporate sustainability ( $\mathrm{cr} \rightarrow \mathrm{cs}$ )

2) Mono-focal corporate sustainability (CS1)

2a) Corporate sustainability as moral leadership (cs/moral)

2b) Corporate sustainability as a strategy (cs/strategic)

3) Inclusive approaches to corporate sustainability (CSn)

3a) Corporate sustainability as a holistic concept $(\operatorname{cs} \infty)$

3b) Corporate sustainability as part of the triple bottom line (csTBL)

3c) Corporate sustainability as a financial incentive (cs\$)

3d) Corporate sustainability as an indexing exercise (cs/index)

The typology presented above shows that there is no consensus in the literature on defining sustainability and on which enterprises' activities fully correspond to this idea. In some cases, there is a partial agreement on the method of defining the analyzed term, while in others one can even speak of an opposite means of interpretation. A solution to this problem may be the use of the widest possible definition which covers all aspects of the issue. However, in this case, some authors might object to 
such a solution, due to their clearly emphasized separateness of sustainability in relation to corporate responsibility. The considered issue becomes even more complicated when, despite the lack of a precise definition, the idea of sustainability is used as a reference point to define the sustainable business model archetypes. The key concept here is sustainable innovations, which cover three categories: technological, social and organizational [27]. It is a conceptual base allowing us to describe, in detail, eight sustainable business model archetypes [28]:

1) Maximize material productivity and energy efficiency-Do more with fewer resources, generating less waste, emissions and pollution. The limitation of this archetype relates to the rebound effect [29] and the stimulation of unemployment [30].

2) Create value from "waste"-The concept of "waste" is eliminated by turning waste streams into useful and valuable inputs to other production and making better use of under-utilized capacity. The limitation of this archetype results from the artificiality of the concept of "waste" itself in the context of the activities of commercial organizations [31,32].

3) Substitute with renewables and natural processes-Reduce environmental impacts and increase business resilience by addressing resource constraint "limits to growth", associated with non-renewable resources and current production systems. The limitation of this archetype results from the insufficient pace of development of the necessary technologies in relation to the needs related to population growth and the need to improve its standard of living.

4) Deliver functionality, rather than ownership—Provide services that satisfy users' needs without their having to own physical products. The limitation of this archetype results from doubts in relation to Product Service Systems' eco-efficiency [33] and also from doubts that such a solution raises the opinions of consumers [34].

5) Adopt a stewardship role-This involves proactively engaging with all stakeholders to ensure their long-term health and well-being. The limitation of this archetype results from the difficulties that arise when trying to take into account the interests of all stakeholders at the same time.

6) Encourage sufficiency-Solutions that actively seek to reduce consumption and production. The limitation of this archetype is due to the fact that solutions introduced unilaterally by the organization often do not bring an effect due to the lack of systemic adjustments in society [35].

7) Re-purpose the business for society/environment-This involves prioritizing the delivery of social and environmental benefits rather than economic profit (i.e., shareholder value) maximization, through close integration between the firm and local communities and other stakeholder groups. The traditional business model, where the customer is the primary beneficiary, may shift. Again (similar to the fifth archetype) the limitation of this archetype results from the difficulties that arise when trying to take into account the interests of all stakeholders at the same time.

8) Develop scale-up solutions-This involves delivering sustainable solutions at a large scale to maximize benefits for society and the environment. The limitation of this archetype is due to the fact that it is mainly small start-ups that are a source of innovation with the right potential for change, which sometimes hinders their sufficiently effective dissemination [36,37].

The above considerations show that there is still a lack of universal comprehensive dimensions for describing sustainability and other phenomena and concepts based on this idea. The diversity of points of view on this complex subject is a very extensive issue $[38,39]$. The lack of a common consensus regarding the terminology used is a significant barrier limiting the comparison of individual concepts or theoretical models presented by subsequent research centers. It should be recognized that the described problem has blurred boundaries due to the qualitative nature of the phenomena studied. Nevertheless, each new attempt to organize the analyzed matter broadens the available horizon of cognition, opens new interpretative possibilities and enriches the available knowledge and raises the understanding of relationships in this area. Therefore, the question of how organizations look at themselves in the context of the idea of sustainability becomes cognitively valuable. The literature devoted to this subject is dominated by the perspective presenting a point of view characteristic of the 
theoreticians' environment. The concepts they propose are disseminated and are widely used-also in management practice. Decision-makers interpret popularized ideas in their own way, referring to them in accordance with how they understand them. That is why, in the present considerations, the thesis was adopted that the context in which the entity refers to the idea of sustainability reveals the dimensions (semantic categories) within the framework of which the entity determines its attitude to this idea. Qualitative analysis of the context of referring to sustainability in the annual financial reports of the largest global information-based companies, allows us to attempt to identify key universal dimensions of self-determination, which directly refer to the examined idea. Acquiring knowledge in this area will allow for at least partial confrontations of both perspectives: those of the theoreticians and those of the practitioners of management.

\section{Methods}

Qualitative Data Analyses is a set of research methods that is significantly gaining importance due to its ever-wider access to extensive collections of documents containing non-quantitative records and having a nature that excludes the possibility of making simple comparisons [40]. It is about finding key elements of content and relationships that create context. The rule here is that the data are selected not because of their representativeness, but because of their diversity. It is assumed that the analyzed data set does not have to take into account all of the cases characteristic of the studied phenomenon. Subsequent research may provide new observations that will broaden the knowledge already available but, at the same time, will absolutely not invalidate previous observations. This means that, within the presented study, if it is possible to identify any semantic categories that are within the dimensions that are sought, then further studies may in the future expand the list of such dimensions. This is a simple consequence of the fact that there is no such thing as an average context of referring to the concept of sustainability because we are dealing here with a linguistic analysis of meanings. Because the set of meanings and interpretations is infinitely large, therefore, the purpose of qualitative research is to gradually discover the meta-level of the context, which is created by schematic narrative threads visible in current public discourse. The results of qualitative research are, on the other hand, the basis for formulating statistical hypotheses tested as part of quantitative research, being a continuation of the presented research process. Therefore, it is only in the future-if the research is continued - that there may appear a demand for data representativeness. This situation will, inter alia, concern an interesting question about the actual frequency of reaching for individual semantic categories in public discourse (clarifying this issue would allow us to determine the types of narratives used by individual enterprises); however, this is not the subject of the currently presented analysis. In the modern world, the exploration of this type of cognitive space often brings new and very valuable insights, expanding the available knowledge and opening new research fields. It is not about obtaining the value of representativeness of the conducted analyses, but only about observing the characteristic symptoms of previously unnoticed phenomena and dependencies confirming the existence of these phenomena. Therefore, in this case, there is no need to comment on the frequency of occurrence of a given observation in the studied population because the fact of even a single finding of the occurrence of some significant phenomenon is important [41]. Each occurrence of data has the same importance regardless of whether it was repeated in the population under consideration and regardless of who the object of observation was (however, in-depth statistical research should be possible based on the results of qualitative analyses as the next stage of the cognitive process). Each entity participating in the study can be a source of any extensive set of data because, at the stage of data analysis, the data origin does not matter.

When designing the study, a single sentence was adopted as the unit of analysis in the study. Such a sentence had to contain the word "sustainability" (or any related derived version). This choice was made because of the will to eliminate any interpretation doubts about observing non-direct relationships between concepts. From each of the identified sentences, concepts forming the basic context of the appearance of the term sustainability were extracted. The next step was to develop 
a conceptual map showing the strength of the relationship between the term sustainability and the concepts that create its context. The method of contextual analysis that was applied consisted in identifying all of these terms, which appearing in one sentence with the basic concept (i.e., sustainability) and gained a new meaning due to the way they were placed in the examined document [42]. It is, therefore, important to identify relationships that connect individual concepts. Selected terms could also fulfil the role of complementing the concept modified in the manner just described, thus referring to the idea of sustainability somewhat indirectly. In this way, it was possible to create a network of related concepts around the term sustainability. For example, the independent word "leader" has a different meaning than "leader of sustainability" and both terms differ from the expression "leader of innovations supporting sustainability" (however, both "leader" and "innovation" are an objective part of the context in which the appeal occurred to the idea of "sustainability"). Finally, a strategy of binary opposition analysis was used as the result of inductive approaches and nomothetic explanation [43-45]. This means that, as part of the analysis, criteria were sought that would allow entire groups of terms to be put in a kind of opposition to each other. The aim of the analysis focused on determining the boundaries of the publicly used context of using the term sustainability and the criteria of division of this context. According to the theory, in the case of this type of qualitative basic research, the principle of seeking criteria of any nature was in force-provided that the final conclusions lead to the creation of a logically defensible model.

At the coding stage-i.e., creating a data set for later analysis (the set consisting of single words or complex expressions) - it was assumed that the value of Holsti's intercoder reliability factor must be at least $90 \%$. However, to ensure that the results of the data analysis had the attribute of trustworthiness (which is the equivalent of validity in quantitative studies), data and investigator triangulation and reverse hypothesis triangulation were used. At the analysis stage, the hypothesis was adopted that the set of analyzed expressions can be divided into subsets while using at least one pair of categories in binary opposition to each other. It should be remembered that exploratory research was not intended to carry out any measurement (especially of a nature of standardized measurement, as in the case of psychometrics) because their only purpose was to interpret meanings - the interpretation leading to giving the name to potentially existing collective semantic categories (which were expected to be identified). Therefore, in this case, trustworthiness was based solely on the triangulation process. In the presented study, this process consisted in the fact that the set of all expressions, identified as the context of references to the idea of sustainability, was the subject of analysis repeated three times. Each analysis was aimed at dividing the set on the basis of the method of detecting categories constituting binary oppositions.

A binary opposition is a pair of related concepts that divide cognitive space into two subspaces (not necessarily equally extensive), which define two categories of meaning facing each other. So, in the case of searching for binary oppositions, the conduction of the research process leads to defining a contrast between two mutually exclusive terms. The method of identifying binary opposition (as a crucial concept of structuralism), uses such distinctions which are fundamental to human intellect. In structuralism, a binary opposition is seen as a fundamental organizer of human perception. The exploratory nature of such methodology makes it impossible to talk about variables in a classical meaning. So, the essence of the whole procedure is to detect natural binary structures without making any previous assumptions about their shape and number. A tool that allows us to optimally achieve this goal (in the context of the issue considered in the title of the paper) is to carry out interviews in the form of classical focus groups. The analyses were carried out by three research teams (focus groups) that used all or random subsets from among all expressions constituting the examined context. The research teams included managers and entrepreneurs bound to the studied industry (created by information-based companies). The successfully identified categories had to be the result of the observations made by each of the three teams to be considered as something actually observed. Finally, an independent team of experts was tasked with using already identified categories and assigning each concept contained in the examined set to one of the categories detected by previously working 
teams (thereby, a reversal of the order of actions was used to search for the elements of the set which could not possibly match any category).

The original research material were annual financial reports delivered to the US Securities and Exchange Commission by selected global information-based companies. Such a document is the most important as it is informative of the company's standard and publicly available reports (referring to its activities). An official annual financial report contains a substantive synthesis of all key problems-and also those defined from the perspective of sustainability (according to the way of understanding this concept within the organization)—identified by the top management staff. This document is signed by the corporate board (thus expressing its position on key issues) and analyzed by all stakeholders. Twenty reports published by enterprises that are leaders in the data processing sector were selected as data sources for analysis: Accenture PLC, Akamai Technologies, Alibaba Group Holding Ltd., Alphabet Inc., Amazon.com Inc., Atlassian Corporation, Automatic Data Processing Inc., Baidu Inc., Cerner Corp., Cisco Systems Inc., IAC Interactive Corp., Match Group Inc., Microsoft Corp., Oracle Corp., PayPal Holdings Inc., Sea Limited, Servicenow Inc., Spotify Technology S.A., Tencent Music Entertainment Group, Yandex N.V. At the stage of selecting reports, some were rejected because they did not include references to the concept of sustainability (among others, these were the reports published by: Apple Inc., Facebook Inc., IBM International Business Machines Corp. and Twitter Inc.).

\section{Results}

In the annual report of Accenture PLC [46], three units of analysis were identified, in which the term sustainability (or any related derived version) appeared three times. At least eighteen different terms were a direct reference to this main concept, defining its basic context (in order to ensure the transparency of the analysis, the focus was on the concepts recognized as key to understanding the emerging context). In the annual report of Akamai Technologies [47], one unit of analysis was identified, in which the term sustainability (or any related derived version) appeared once. At least two different terms were a direct reference to this main concept, defining its basic context. In the annual report of Alibaba Group Holding Ltd. [48], thirteen units of analysis were identified, in which the term sustainability (or any related derived version) appeared fourteen times. At least twenty-three different terms were a direct reference to this main concept, defining its basic context. In the annual report of Alphabet Inc. [49] two units of analysis were identified, in which the term sustainability (or any related derived version) appeared three times. At least nineteen different terms made a direct reference to this main concept, defining its basic context. In the annual report of Amazon.com Inc. [50] two units of analysis were identified in which the term sustainability (or any related derived version) appeared twice. At least two different terms were a direct reference to this main concept, defining its basic context. In the annual report of Atlassian Corporation [51], one unit of analysis was identified, in which the term sustainability (or any related derived version) appeared once. At least five different terms were a direct reference to this main concept, defining its basic context. In the annual report of Automatic Data Processing Inc. [52], one unit of analysis was identified, in which the term sustainability (or any related derived version) appeared once. At least four different terms were a direct reference to this main concept, defining its basic context. In the annual report of Baidu Inc. [53], one unit of analysis was identified in which the term sustainability (or any related derived version) appeared once. At least two different terms were a direct reference to this main concept, defining its basic context. In the annual report of Cerner Corp. [54], two units of analysis were identified, in which the term sustainability (or any related derived version) appeared twice. At least five different terms were a direct reference to this main concept, defining its basic context. In the annual report of Cisco Systems Inc. [55], two units of analysis were identified, in which the term sustainability (or any related derived version) appeared twice. At least four different terms were a direct reference to this main concept, defining its basic context. In the annual report of IAC Interactive Corp. [56], two units of analysis were identified, in which the term sustainability (or any related derived version) appeared twice. At least two different terms were a direct reference to this main concept, defining its basic context. In the annual report of 
Match Group Inc. [57], one unit of analysis was identified, in which the term sustainability (or any related derived version) appeared once. At least two different terms were a direct reference to this main concept, defining its basic context. The Microsoft Corp. annual report [58] identified one unit of analysis in which the term sustainability (or any related derived version) appeared once. At least six different terms made a direct reference to this main concept, defining its basic context. In the annual report of Oracle Corp. [59], one unit of analysis was identified, in which the term sustainability (or any related derived version) appeared once. At least two different terms were a direct reference to this main concept, defining its basic context. In the annual report of PayPal Holdings Inc. [60], two units of analysis were identified, in which the term sustainability (or any related derived version) appeared twice. At least five different terms were a direct reference to this main concept, defining its basic context. In the annual report of Sea Limited [61], two units of analysis were identified, in which the term sustainability (or any related derived version) appeared twice. At least six different terms were a direct reference to this main concept, defining its basic context. In the annual report of Servicenow Inc. [62], two units of analysis were identified, in which the term sustainability (or any related derived version) appeared twice. At least two different terms were a direct reference to this main concept, defining its basic context. In the annual report of Spotify Technology S.A. [63], one unit of analysis was identified, in which the term sustainability (or any related derived version) appeared once. At least six different terms were a direct reference to this main concept, defining its basic context. In the annual report of Tencent Music Entertainment Group [64], three units of analysis were identified, in which the term sustainability (or any related derived version) appeared three times. At least twelve different terms were a direct reference to this main concept, defining its basic context. In the annual report of Yandex N.V. [65], one unit of analysis was identified, in which the term sustainability (or any related derived version) appeared once. At least two different terms were a direct reference to this main concept, defining its basic context.

Overall, at least seventy-two different concepts, some of which appeared repeatedly, were found to be significant in determining the context of referring to the idea of sustainability. Repetitions took place both for the content of a single report and several independent reports. In individual cases, certain terms were used up to four times. An interesting observation is the fact that no term was universal enough for each of the examined entities to consider it appropriate to be used (there were situations when certain terms were used by six entities simultaneously). Generally, in the dominant part, the identified word lists formed disjoint sets. Despite the high degree of differentiation (in the language layer) of the ways in which individual entities referred to the idea of sustainability, there were some axes of division within the identified set of terms. The above remarks are intended to pre-illustrate the observations made and to inspire the carrying out of the essential part of searching for the potential dimensions of self-determination in the context of the idea of sustainability. This task will be accomplished by searching for and analyzing areas that are examples of binary oppositions. In the identified set of concepts—at the highest level of generality - it is possible to distinguish terms that refer to the entity (itself) issuing the examined document or to the way of conducting business (e.g., business, company, core business, effort, excellence, flexibility, growth, long run, long-term, mission, product, production, quality, resource-efficiency, technology, value, vision) and such terms that clearly relate to the entity's relationship with the environment or to the environment itself (e.g., advocate, climate change, community, environment, government, healthcare, human rights, partnership, poverty, protection, villager, women, world). Therefore, if we assume that we are dealing with two contextual sub-areas in which references to the idea of sustainability are formulated, then in each of them an attempt can be made to identify the occurrences of possible binary oppositions. In the first case, twenty-one terms:

acquisition, business, capital, company, core business, cost, e-commerce, growth, industry, investment, margin, operation, product, production, quality, report, resource-efficiency, service, strategy, supply chain, technology 
point to the entity itself and relate to very explicit and specific matters (so this dimension will be called BASE and the fundamental question that can be asked here is: "With what tools and by what means is the organization ready to implement the idea of sustainability?"), while the other nineteen terms focus on immeasurable, universal ideas:

culture, change, community, effort, examination, excellence, flexibility, information, innovation, long run, long-term, mission, safety, security, philosophy, protection, relationship, value, viability, vision

(so, this dimension will be called IDEA and the fundamental question that can be asked here is: "What paradigm and what logic shapes the interior of an organization that is sensitive to the idea of sustainability?"). However, when it comes to the context arising at the interface between the subject and its environment, the division of the terms used on such occasions results from the role played by the organization in this system. In this case one could point to the organization's active behavior:

activist, advocate, businessman, competitor, entrepreneur, leader, precursor, partner, protector

(so, this dimension will be called ROLE and the fundamental question that can be asked here is: "What role does the organization want to take, which is sensitive to the idea of sustainability?") or its passive participation in supporting certain concepts and treating them with respect:

benefit, climate change, consumer, education, environment, electricity, government, green electricity, healthcare, human rights, individual, live, non-profit organization, renewable energy, resources, stakeholders, poverty, rural commerce, user, villager, women, world

(so, this dimension will be called CARE and the fundamental question that can be asked here is: "What draws the attention of an organization sensitive to the idea of sustainability?").

\section{Discussion and Conclusions}

\subsection{Binary Oppositions As the Basis of Identified Dimensions of Self-Determination}

The self-determination dimensions initially identified in the previous point of discussion need to be clarified. The BASE dimension represents a way of defining an entity from the perspective of improving the entity's interior through the prism of specific, measurable goals, ventures, projects, and specific decisions intending to give it the attributes of an organization recognized as meeting the requirements of sustainability. The IDEA dimension represents a way of defining an entity from the perspective of attempts focused on the adaptation of its internal philosophy and logic of operation to the idea of sustainability. The ROLE dimension represents a way of defining an entity from the perspective of the active role it wants to play in relation to the environment, shaping it in a manner consistent with the idea of sustainability. The CARE dimension represents a way of defining an entity from the perspective of a reactive observer who is sensitive to the needs of the environment and treats those needs with respect because he sees it as a justification for his further existence and for the place he occupies in relation to the environment. Thus, the identified binary oppositions are as follows: interior-exterior (two categories in basic opposition); execution-creation (within basic category interior); initializing-responding (within basic category exterior).

\subsection{Dimensions of Self-Determination Towards Theories Devoted to the Idea of Sustainability}

Recognizing the dimensions that determine the ways of referring to the idea of sustainability (on the occasion of the process of self-determination) is a factor that allows us to look in a new way at the most important conceptions for which sustainability is the basic reference point. These types of conceptions, together with the dimensions that were detected, can help in determining the profile that a single organization adopts while carrying out its self-determination, which takes into account the perspective of sustainability. The analysis of challenges arising from creating Sustainable Business 
Models shows that, in the case of Triple Bottom Line, the three balanced dimensions come to the fore: BASE, ROLE and CARE (representing excellence on operation level, external initiative and response for the external needs). The Mind-Set challenge is close to what IDEA expresses (stimulating creativity by breaking mental barriers). Challenges related to Resources and Technology Innovation as well as Business Modelling Methods and Tools, in turn, mainly draw attention to the BASE dimension (due to the focus on performance efficiency). Finally, External Relationships is a challenge that primarily indicates the dimensions of ROLE and CARE (because of the focus on various relationships with the environment). The rules defined in the Natural Step conception generally express the same message that is contained in the CARE dimension (all postulates are to indicate to the organization how to respond to the needs of the environment). Four detected dimensions could also be used while describing the Typology of Corporate Sustainability (presented by M. M. Bergman, Z. Bergman and L. Berger). In the case of the type marked as 1, the starting point is the concept of "corporate responsibility" (which is consistent with what the CARE dimension expresses). The way of referring to this concept (while defining the term sustainability) can take the form of identification, opposition or succession-by choosing one from these three possible relationships, individual subtypes A, B, C of sustainability definition are designated. In the case of the type marked as 2 , sustainability is understood through the prism of leadership in initiating phenomena beneficial for the environment (which corresponds to the proposed dimension ROLE) or the general philosophy of the organization (which reflects the IDEA dimension). In the case of the type marked as 3, the concept of sustainability is defined in incremental logic because, in the group of four subtypes, there is one of a holistic nature (which corresponds to the range of four proposed dimensions simultaneously) while the other subtypes mainly describe the perfection of operational activities (which can be largely identified with the BASE dimension). It is also possible to define eight Sustainable Business Model Archetypes from a four-dimensional perspective. Archetype No. 1-focusing on productivity and efficiency-is, in a natural way, associated with the BASE dimension. Archetype No. 2-focusing on waste elimination-is, in a natural way, associated with the BASE/CARE dimensions (because of the postulate of cost reduction and reduction in environmental burdens). Archetype No. 3 is associated with the CARE dimension (thanks to care about the reduction in environmental impact). Archetype No. 4 is associated with the IDEA dimension because of the postulate of changing the philosophy of traditional business purpose to be more friendly for the environment. Archetype No. 5-focused on adopting a stewardship role-is associated with the ROLE dimension. Archetype No. 6 is associated with the ROLE/CARE dimensions because of the fact that it assumes the active promotion of a reduction in consumption and production. Archetype No. 7 is associated with the IDEA/CARE dimensions because of the redefinition of the benefit category (from economic into environmental). Archetype No. 8 is associated with the BASE/ROLE dimensions on the occasion of focusing on operating in such a way that the benefit for society and the environment will be maximized.

\subsection{Proposals Referring to the Direction of Practical Use of Dimensions of Self-Determination}

The key to the applicability of the four dimensions (described in the present discussion), regarded as a common denominator (which is used to compare different conceptions built around the term of sustainability), is to create standards for assessing the scope within which the self-determination of the organization takes into account the features characterizing each of the listed dimensions. Only then is it be possible to precisely show, by means of a four-dimensional model, the relationships that occur between individual archetypes, subtypes and sustainability challenges (representing various classifications found in the literature). Assessment standards (the need to define them sets the direction for further research) would allow for the preparation of self-determination characteristics of any single organization in accordance with how the organization treats the idea of sustainability, which would then allow us to translate the results of the assessment into an indication of the challenges which the organization takes into account in its plans, as well as the archetypes and subtypes that the organization represents, and also those-known from theories—-principles (e.g., The Natural Step rules) that the 
organization implements. Standards aimed at assessing the dimensions that were detected as part of the presented analysis can be based on a hierarchical system. At the first level (of "awareness"), words forming an ordered context, under which a particular enterprise refers to the idea of sustainability, must be assessed in terms of formal compliance. The ordered context consists of four sets of words, each representing the answers to one basic question (out of four questions formulated as a summary of the results section, one for each of the four dimensions), while formal compliance means that the idea of sustainability has been recalled correctly (reflecting how it is understood in theoretical terms). Such action is aimed at detecting abuse (i.e., cases of invoking the idea of sustainability in an instrumental way which contradicts its common understanding; for example, for marketing purposes only). At the second level (defined as the level of "actions"), the assessment concerns whether the document examined in the passage, in which references to the main idea were noted, allows for answering the following question: "Is it possible to indicate specific actions that the company plans to take in relation with what the concrete dimension of striving for sustainability means to it?" At the third level (defined as the level of "beneficiaries"), the assessment concerns whether it is possible to indicate the beneficiaries of the activities that the organization plans to take in relation to what a specific dimension of striving for sustainability means to it. Finally, at the fourth level (defined as the level of "effects"), the evaluation assesses whether it is possible to indicate specific benefits that will be obtained by the beneficiaries through the activities of the organization (planned by it in relation to what a specific dimension of striving for sustainability means to it). There should be an assumption here that, only when it is possible to formulate a satisfactory answer to a question posed in the framework of the assessment of a particular level, it is permissible to proceed to the next level of the assessment. Carrying out the assessment in the presented way may mean that each dimension will reach a different level. The usefulness of the four-dimensional model is also due to the fact that it allows is to prepare well-argued quantitative statistical studies that lead to the organization's self-determination classification, using cluster analysis and the empirical typification of real attitudes conditioned by their stance on the idea of sustainability. Such results would allow for the verification of the theoretical classifications, which were discussed in the analysis.

\subsection{Dimensions of Self-Determination Versus an Alternative Way of Categorizing Context}

The proposed standards for assessing the four dimensions of self-determination to some extent correspond with the GRI matrix referenced in the background section. These dimensions alone can partly be equated with the leading "Categories" used in the GRI matrix. The main difference here is that, instead of an arbitrarily determined set of superior Categories, it was proposed to distill the most general level of meaning by identifying primary dichotomies in a disordered set of terms used by an organization on the occasion of referring to the idea of sustainability. However, the scheme of presenting the topics of narration, as used inside the GRI matrix, can be transformed into the following form: Action, Tool, Beneficiary. This new scheme is very close to the proposed four levels of standards for assessing self-determination dimensions. The key difference here is the lack of gradation of the assessment in the GRI matrix (individual parts of the diagram may remain unfilled, which does not prevent passing on to the next ones). For example, the topic of narration defined in the GRI matrix as: "environmental (Category) impact of energy consumption (Topic) caused by data centers (Specification) of organization (Constituency)" contains all three basic elements, while the topic of narration "environmental (Category) impact of electronic waste (Topic) produced by business (Constituency)" omits the "Specification" element. However, this situation does not affect the relative position of this second topic of narration in relation to all others. If the elements of the GRI matrix bearing the names Topic (Action) and Specification (Tool) are combined into one term, the latter will reflect the meaning that has been assigned to the second level of the standard for assessing the dimensions of self-determination. It should be noted that the GRI matrix does not deal with the issue of specific effects (positive or negative) that later become the beneficiary's participation, while the 
fourth level of the standard for assessing self-determination dimensions does deal precisely with the issue of specific effects.

\subsection{The Final Conclusions}

The main contribution of the presented considerations consists of the elaboration of the concept of dimensions of self-determination from the perspective of the idea of sustainability. In particular, the role, place and significance of these dimensions were determined in the process of research, analysis and the implementation of the idea of sustainability in the practice of economic life in relation to the information-based sector. The purpose of identifying the structure of semantic connections, occurring within a set of narratives, is not to generalize (in a statistical sense) but to ask the right questions. Future statistical surveys can clarify a number of key issues that have significant implications for the practice of implementing sustainability. These include questions such as: "Which specific concepts most often represent each dimension?", "Which dimensions are statistically more often used by corporations?", "What do the statistics look like when it comes to the levels of use of each dimension that are subject to evaluation?", "Do there exist the profiles of using dimensions (i.e., is there diversity of patterns due to the level of use of individual dimensions), which divide the population of enterprises into smaller groups (clusters)?", "Is the narrative profile (the choice of dimensions and the level of their use by the company) correlated with the actual actions taken to implement the idea of sustainability?", "What knowledge about the company's behavior is given by knowing its narrative profile?" and "If a correlation is found between the company's narrative profile and the activities it undertakes, is there an inverse relationship in line with the assumptions of behavioral economics (that is, by stimulating a particular type of narrative, can one induce enterprises to take specific actions)?" These and similar questions have important practical implications and provide inspiration and motivation for further research. It seems that the four-dimensional model assumptions proposed in the considerations have high practical value and can be a valuable inspiration for further research and discussion in the scientific community dealing with the discussed issues.

Funding: This research received no external funding.

Conflicts of Interest: The author declares no conflict of interest.

\section{References}

1. Lorenz, M.H. Information Technology and Sustainability: Essays on the Relationship between ICT and Sustainable Development; BoD—Books on Demand: Zurich, Switzerland, 2008.

2. Zink, K.J. Corporate Sustainability as a Challenge for Comprehensive Management; Springer Science \& Business Media: Berlin/Heidelberg, Germany, 2008.

3. Lakoff, G. Why it Matters How We Frame the Environment. Environ. Commun. 2010, 4, 70-81. [CrossRef]

4. Gibson, C.H. Financial Reporting and Analysis; Cengage Learning: Boston, MA, USA, 2012.

5. Carroll, A.B.; Brown, J.; Buchholtz, A.K. Business E Society: Ethics, Sustainability E Stakeholder Management; Cengage Learning: Boston, MA, USA, 2017.

6. Jackson, A.Y.; Mazzei, L.A. Thinking with Theory in Qualitative Research; Informa UK Limited: London, UK, 2011.

7. Barrett, R. The Values-Driven Organization: Cultural Health and Employee Well-Being as a Pathway to Sustainable Performance; Taylor \& Francis: London, UK, 2017.

8. Landrum, N.E.; Ohsowski, B. Identifying Worldviews on Corporate Sustainability: A Content Analysis of Corporate Sustainability Reports. Bus. Strat. Environ. 2017, 27, 128-151. [CrossRef]

9. Calabres, A.; Costa, R.; Ghiron, N.L.; Menichini, T. Materiality analysis in sustainability reporting: A tool for directing corporate sustainability towards emerging economic, environmental, and social opportunities. Technol. Econ. Dev. Econ. 2019, 25, 1016-1038. [CrossRef]

10. Sustainability Topics for Sectors: What Do Stakeholders Want to Know? Research \& Development Series; The Global Reporting Initiative (GRI): Amsterdam, The Netherlands, 2013. 
11. de Mendonca, T.; Zhou, Y. When companies improve the sustainability of the natural environment: A study of large U.S. companies. Bus. Strat. Environ. 2019, 29, 801-811. [CrossRef]

12. Hanohov, R.; Baldacchino, L. Opportunity recognition in sustainable entrepreneurship: An exploratory study. Int. J. Entrep. Behav. Res. 2018, 24, 333-358. [CrossRef]

13. Thomson, S.B. Sample Size and Grounded Theory. J. Adm. Gov. 2011, 1, 45-52.

14. Creswell, J. Qualitative Inquiry \& Research Design: Choosing among Five Approaches; Sage Publications: Thousand Oaks, CA, USA, 2007.

15. Herman, R.P. The HIP Investor. Make Bigger Profits by Building a Better World; John Wiley \&Sons Inc.: Hoboken, NJ, USA, 2010.

16. D'Humieres, P. Towards a Sustainable European Business Model? Foundation Robert Schuman: Paris, France, 2018.

17. Schaltegger, S.; Lüdeke-Freund, F.; Hansen, E.G. Business Models for Sustainability-A Co-Evolutionary Analysis of Sustainable Entrepreneurship, Innovation, and Transformation, Organization \& Environment. SAGE J. 2016, 264-289.

18. Eggert, A.; Ulaga, W.; Frow, P.; Payne, A. Conceptualizing and communicating value in business markets: From value in exchange to value in use. Ind. Mark. Manag. 2018, 69, 80-90. [CrossRef]

19. Jabłoński, M. Value Migration to the Sustainable Business Models of Digital Economy Companies on the Capital Market. Sustainability 2018, 10, 3113. [CrossRef]

20. Evans, S.; Vladimirova, D.; Holgado, M.; Van Fossen, K.; Yang, M.; Silva, E.; Barlow, C.Y. Business Model Innovation for Sustainability: Towards a Unified Perspective for Creation of Sustainable Business Models. Bus. Strat. Environ. 2017, 26, 597-608. [CrossRef]

21. Slaper, T.F.; Hall, T.J. The Triple Bottom Line: What Is It and How Does It Work? Indiana Bus. Rev. 2011, 4-8.

22. Elkington, J. 25 Years Ago I Coined the Phrase “Triple Bottom Line". Here's Why It's Time to Rethink It. Harvard Business Review. 2018; pp. 2-5. Available online: https://hbr.org/2018/06/25-years-ago-i-coinedthe-phrase-triple-bottom-line-heres-why-im-giving-up-on-it (accessed on 10 July 2019).

23. Scerri, A.; James, P. Accounting for sustainability: Combining qualitative and quantitative research in developing 'indicators' of sustainability. Int. J. Soc. Res. Methodol. 2010, 13, 41-53. [CrossRef]

24. Lozano, R. Towards better embedding sustainability into companies' systems: An analysis of voluntary corporate initiatives. J. Clean. Prod. 2012, 25, 14-26. [CrossRef]

25. Robèrt, K.-H. Tools and concepts for sustainable development, how do they relate to a general framework for sustainable development, and to each other? J. Clean. Prod. 2000, 8, 243-254. [CrossRef]

26. Bergman, M.M.; Bergman, Z.; Berger, L. An Empirical Exploration, Typology, and Definition of Corporate Sustainability. Sustainability 2017, 9, 753. [CrossRef]

27. Boons, F.; Lüdeke-Freund, F. Business models for sustainable innovation: State-of-the-art and steps towards a research agenda. J. Clean. Prod. 2013, 45, 9-19. [CrossRef]

28. Bocken, N.; Short, S.; Rana, P.; Evans, S. A literature and practice review to develop sustainable business model archetypes. J. Clean. Prod. 2014, 65, 42-56. [CrossRef]

29. Herring, H.; Sorrell, S. Energy Efficiency and Sustainable Consumption: The Rebound Effect; Palgrave Macmillan: London, UK, 2009.

30. Ashford, N.; Hall, R.P.; Ashford, R.H. The crisis in employment and consumer demand: Reconciliation with environmental sustainability. Environ. Innov. Soc. Trans. 2012, 2, 1-22. [CrossRef]

31. Lambert, A.; Boons, F. Eco-industrial parks: Stimulating sustainable development in mixed industrial parks. Technovation 2002, 22, 471-484. [CrossRef]

32. Gibbs, D.; Deutz, P. Reflections on implementing industrial ecology through eco-industrial park development. J. Clean. Prod. 2007, 15, 1683-1695. [CrossRef]

33. Mont, O.; Tukker, A. Product-Service Systems: Reviewing achievements and refining the research agenda. J. Clean. Prod. 2006, 14, 1451-1454. [CrossRef]

34. Catulli, M. What uncertainty? Further insight into why consumers might be distrustful of product service systems. J. Manufac. Technol. Manag. 2012, 23, 780-793. [CrossRef]

35. Jackson, T. Prosperity without Growth; Informa UK Limited: Colchester, UK, 2009.

36. Nerkar, A.; Shane, S. When do start-ups that exploit patented academic knowledge survive? Int. J. Ind. Organ. 2003, 21, 1391-1410. [CrossRef] 
37. Giarratana, M. The birth of a new industry: Entry by start-ups and the drivers of firm growth. Res. Policy 2004, 33, 787-806. [CrossRef]

38. Bawa, K.S.; Seidler, R. Dimensions of Sustainable Development_Volume I; EOLSS Publications: Abu Dhabi, UAE, 2009.

39. Bawa, K.S.; Seidler, R. Dimensions of Sustainable Development-Volume II; EOLSS Publications: Abu Dhabi, UAE, 2009.

40. Creswell, J.W.; Creswell, J.D. Research Design: Qualitative, Quantitative, and Mixed Methods Approaches, 5th ed.; SAGE: Los Angeles, CA, USA, 2018.

41. Shelley, M.; Krippendorff, K. Content Analysis: An Introduction to its Methodology. J. Am. Stat. Assoc. 1984, 79, 240. [CrossRef]

42. Agarwal, N.K. Exploring Context in Information Behavior: Seeker, Situation, Surroundings, and Shared Identities. Synth. Lect. Inf. Concepts Retr. Serv. 2017, 9. [CrossRef]

43. Feldman, M. Strategies for Interpreting Qualitative Data; SAGE Publications: Los Angeles, CA, USA, 1995.

44. Gibbs, G.R. Analysing Qualitative Data; SAGE Publications: Los Angeles, CA, USA, 2008.

45. Kuckartz, U. Qualitative Text Analysis: A Guide to Methods, Practice E Using Software; SAGE Publications: Los Angeles, CA, USA, 2014.

46. Annual Report Accenture PLC, Form 10-K (dated 31 August 2019). Available online: https://www.sec.gov/ix? doc=/Archives/edgar/data/1467373/000146737319000339/acn831201910k.htm (accessed on 30 January 2020).

47. Annual Report Akamai Technologies Inc., Form 10-K (dated 31 December 2018). Available online: https://www.sec.gov/Archives/edgar/data/1086222/000108622219000066/akam10k123118.htm (accessed on 30 January 2020).

48. Annual Report Alibaba Group Holding Ltd., Form 20-F (dated 31 March 2019). Available online: https://www. sec.gov/Archives/edgar/data/1577552/000104746919003492/a2238953z20-f.htm (accessed on 30 January 2020).

49. Annual Report Alphabet Inc., Form 10-K (dated 31 December 2018). Available online: https://www.sec.gov/ Archives/edgar/data/1652044/000165204419000004/goog10-kq42018.htm (accessed on 30 January 2020).

50. Annual Report Amazon.com Inc., Form 10-K (dated 31 December 2018). Available online: https: //www.sec.gov/Archives/edgar/data/1018724/000101872419000004/amzn-20181231x10k.htm (accessed on 30 January 2020).

51. Annual Report Atlassian Corporation PLC, Form 20-F (dated 30 June 2019). Available online: https://www. sec.gov/Archives/edgar/data/1650372/000165037219000020/a20-f06302019.htm (accessed on 30 January 2020).

52. Annual Report Automatic Data Processing Inc., Form 10-K (dated 30 June 2019). Available online: https: //www.sec.gov/Archives/edgar/data/8670/000000867019000021/q4fy1910k.htm (accessed on 30 January 2020).

53. Annual Report Alibaba Baidu Inc., Form 20-F (dated 31 December 2018). Available online: https://www.sec. gov/Archives/edgar/data/1329099/000119312519076779/d657854d20f.htm (accessed on 30 January 2020).

54. Annual Report Cerner Corp., Form 10-K (dated 29 December 2018). Available online: https://www.sec.gov/ Archives/edgar/data/804753/000080475319000009/a201810-k.htm (accessed on 30 January 2020).

55. Annual Report Cisco Systems Inc., Form 10-K (dated 27 July 2019). Available online: https://www.sec.gov/ Archives/edgar/data/858877/000085887719000012/csco-2019727x10k.htm (accessed on 30 January 2020).

56. Annual Report IAC Interactive Corp., Form 10-K (dated 31 December 2018). Available online: https://www.sec. gov/Archives/edgar/data/891103/000089110319000006/iac-20181231x10k.htm (accessed on 30 January 2020).

57. Annual Report Match Group Inc., Form 10-K (dated 31 December 2018). Available online: https://www.sec. gov/Archives/edgar/data/1575189/000157518919000020/mtch10-k20181231.htm (accessed on 30 January 2020).

58. Annual Report Microsoft Corporation, Form 10-K (dated 30 June 2019). Available online: https://www.sec. gov/Archives/edgar/data/789019/000156459019027952/msft-10k_20190630.htm (accessed on 30 January 2020).

59. Annual Report Oracle Corp., Form 10-K (dated 31 May 2019). Available online: https://www.sec.gov/ Archives/edgar/data/1341439/000156459019023119/orcl-10k_20190531.htm (accessed on 30 January 2020).

60. Annual Report PayPal Holdings Inc., Form 10-K (dated 31 December 2018). Available online: https://www. sec.gov/Archives/edgar/data/1633917/000163391719000043/pypl201810-k.htm (accessed on 30 January 2020).

61. Annual Report Sea Limited, Form 20-F (dated 31 December 2018). Available online: https://www.sec.gov/ Archives/edgar/data/1703399/000114420419011639/tv512574_20f.htm (accessed on 30 January 2020).

62. Annual Report Servicenow Inc., Form 10-K (dated 31 December 2018). Available online: https://www. sec.gov/ix?doc=/Archives/edgar/data/1373715/000137371519000070/now-20181231x10k.htm (accessed on 30 January 2020). 
63. Annual Report Spotify Technology S.A., Form 20-F (dated 31 December 2018). Available online: https: //www.sec.gov/Archives/edgar/data/1639920/000156459019002688/ck0001639920-20f_20181231.htm (accessed on 30 January 2020).

64. Annual Report Tencent Music Entertainment Group, Form 20-F (dated 31 December 2018). Available online: https://www.sec.gov/Archives/edgar/data/1744676/000156459019012066/tme-20f_20181231.htm (accessed on 30 January 2020).

65. Annual Report Yandex N.V., Form 20-F (dated 31 December 2018). Available online: https://www.sec.gov/ Archives/edgar/data/1513845/000151384519000009/yndx-20181231x20f.htm (accessed on 30 January 2020).

(C) 2020 by the author. Licensee MDPI, Basel, Switzerland. This article is an open access article distributed under the terms and conditions of the Creative Commons Attribution (CC BY) license (http://creativecommons.org/licenses/by/4.0/). 